Invest. pens. crit.

Vol. 2, No. 3, enero- abril 2014.

pp. $59-77$

\title{
Atención a hombres ofensores por el sector salud, de acuerdo a la Ley 38 de 10 de julio de 2001 (introducción)
}

\section{Leiro, C. ${ }^{1, *}$ y Justine, R. ${ }^{1}$}

${ }^{1}$ Clínica Transiciones, No. 47, calle 76, San Francisco, Panamá.

*Autor para correspondencia. Email: cleiro@transiciones.net

Recibido: 15 de marzo de 2014

Aceptado: 15 de abril de 2014

La violencia del hombre hacia la mujer, tradicionalmente, es un hecho que ha sido construido socialmente desde el imaginario de aquello que pertenece a la esfera de lo privado. La violencia hacia las mujeres, en muchos sentidos, cursa el mismo trayecto que el protagonismo y la autonomía de las mujeres. Los estudios de la mujer que se inician en la mitad del siglo pasado ponen en evidencia el vacío que existe en la cultura y la historia de la mujer. La mujer es vista desde lo mítico, desde la madre nutricia y como parte del hombre. La mujer carecía de identidad por sí misma y vinculada a su pareja o como parte de una familia.

Los estudios de la mujer evolucionaron hacia los primeros movimientos feministas (en la década de 1960) y una de las primeras denuncias que formulan es la violencia que comenten los hombres hacia las mujeres, la división del poder y se comienza a realizar una de las transformaciones sociales más intensas del siglo pasado y que se proyectan sobre el momento actual y la violencia, la familia y las relaciones familiares pasan de ser vistas de lo privado a lo público.

La violencia, específicamente la violencia del hombre hacia la mujer, también denominada violencia de género, violencia intrafamiliar o violencia doméstica, es un fenómeno que ha transcurrido a lo largo de nuestra sociedad patriarcal desde tiempos remotos. El patriarcado supone una división en todas las esferas entre hombre y mujer, es realmente con el advenimiento de la propiedad privada que la mujer pierde sus garantías como ser humano. Las raíces del patriarcado son tan antiguas que se remontan a la figura del pater familias, quien podía decidir sobre la vida y la muerte de sus hijos e hijas [vitae necisque potestas - "poder sobre la vida y muerte" (Lagarde, 1997)].

Cuando surge la noción de propiedad privada con el mundo latino (c. 450 a.c.), aparece la práctica de considerar a la mujer como parte de la propiedad de los hombres (sub manu: bajo la 
Invest. pens. crit.

Vol. 2, No. 3, enero- abril 2014.

pp. 59-77

mano). La mujer no podía heredar, tampoco era dueña de sus hijos, cuando era entregada en matrimonio perdía sus dioses en favor de los dioses o ídolos de su esposo, “...para entender la opresión de la mujer es necesario examinar las estructuras de poder que existen en nuestra sociedad. Éstas son: la estructura de clases capitalista, el orden jerárquico de los mundos masculino y femenino del patriarcado y la división racial del trabajo que se practica en una forma muy particular dentro del capitalismo pero que tiene raíces precapitalistas en la esclavitud. El patriarcado capitalista en tanto que sistema jerárquico explotador y opresor requiere de la opresión racial junto con la opresión sexual y la de clase. Las mujeres comparten la opresión unas con otras, pero lo que comparten como opresión sexual es diferente según la clases y las razas, de la misma manera que la historia patriarcal siempre ha dividido y diferenciado a la humanidad según la clase y la raza".

El androcentrismo y el patriarcado (prácticas culturales) son los enunciados bajo los cuales se produce la asimetría, una desproporción cuantitativa y cualitativa del fenómeno de la experiencia humana entre hombres y mujeres. El androcentrismo existe en la medida en que ciertos mitos controlan el status quo, mitos relacionados con la división sexual. Existe la diferenciación sexual, que no es otra cosa que la diferencia genética y fisiológica que existe entre los hombres y las mujeres y, por otro lado, está la diferencia de género, que "es una construcción cultural, cuyo núcleo está integrado por las pautas que la sociedad establece y reproduce sobre el comportamiento esperado (apropiado) del hombre (masculino) y de la mujer (femenino) respectivamente" (Cantera Espinosa, 1999).

Modelo Ecológico de Factores Asociados con la Violencia Infligida por los hombres a las mujeres

Tomado de: Heise, Ellsberg y Gottemöeller, 1999.

\section{Encuadre Histórico: Orígenes de los programas para HOVIFs}

La naturaleza y complejidad de los programas de atención a HOVIF se perfila más adecuadamente cuando se entienden las raíces históricas y los orígenes de éstos programas. Etiony Aldarondo y Fernando Mederos dos investigadores sociales publican en el año 2002 un voluminoso compendio que ha llegado a convertirse en un importante libro de referencia para técnicos que trabajan en el área de atención a HOVIF. El trabajo de Aldarondo y Mederos, publicado por el Civic Research Center y titulado "Programs for Men who Batter: Intervention and Prevention Strategies in a Diverse Society" e una guía forzada para la comprensión de la historia y los cambios y características de los programas de atención a HOVIF. La revisión que sigue está fuertemente cargada de los contenidos y reflexiones de ese trabajo y sirve para hacer un encuadre de los programas de HOVIF.

Los grupos de reeducación para hombres que son abusivos físicamente con sus parejas o esposas, usualmente referidos como programas de intervención para ofensores (PIO), son una nueva 
Invest. pens. crit.

Vol. 2, No. 3, enero- abril 2014.

pp. $59-77$

modalidad de intervención que data no más de veinticinco años. Este capítulo rastrea la historia de este campo. Reseña el desarrollo de los PIOs y explica las metas comunes y estructuras de dichos programas. Este documento está creado como una introducción al campo a aquellos que desean aprender más sobre el mismo y producir reflexiones críticas acerca del pasado y futuro de la disciplina. También ha de analizar el peculiar contexto social y profesional del desarrollo de este campo y sugerirá rutas para su futuro progreso y evolución. Este capítulo está dirigido a los defensores de las mujeres maltratadas, policías, fiscales, jueces, consejeros de intervención en violencia y clínicos.

Aldarondo propone una revisión de la historia del tratamiento de los hombres ofensores comentando que si se realizara una encuesta sobre los PIOs, ésta revelaría que hay cientos de programas entre Estados unidos de América y los países de Europa y América del Sur y Centro América, y que existe una amplia gama de modelos. La revisión de Aldarondo, base de éste acápite se refiere a los programas de atención en Estados Unidos de América. Desde esa perspectiva, es notable que existen programas psicoeducativos (como el modelo "Emerge", el modelo "Duluth" y el programa "Manalive"). También existen modelos que han sido desarrollados por clínicos (como el modelo "AMEND" y los "Talleres de Compasión” de Stosny). Finalmente existen los programas de integración cultural (como el desarrollado por Rhea Almeida); y los modelos cognitivos conductuales (como el modelo de Hamburger).

Una visión más de cerca de estos modelos revelan asombrosas similitudes en sus aproximaciones. Por ejemplo:

- La mayoría de los programas son grupos para hombres. Ni la psicoterapia individual ni la de parejas son modalidades preferidas en la provisión de estos servicios.

- La mayoría de los modelos sigue un encuadre de atención en grupos, bajo un criterio y una estructura psicoeducativa, que típicamente incluye reestructuración cognitiva para deshacer las justificaciones para la conducta abusiva hacia las mujeres y capacitación y entrenamiento en habilidades de automanejo o autocontrol y habilidades interpersonales para mantener la no violencia.

- Ha habido intentos por diferenciar entre aproximaciones psicoeducativas y cognitivoconductuales, sin embargo una apreciación más próxima del contenido de los programas revela que estas dos aproximaciones no poseen diferencias sustanciales.

- La mayoría de los programas no tienen una orientación clínica. No se centran en disfunciones psicológicas, más sí en cambios conductuales y el desarrollo o ampliación de habilidades interpersonales para consolidar un estilo de vida no abusivo y no violento. Algunos programas como AMEND, proveen evaluación clínica y otros servicios, sin embargo los servicios clínicos están en segundo plano en comparación con ayudar a los 
Invest. pens. crit.

Vol. 2, No. 3, enero- abril 2014.

pp. $59-77$

HOVIF a parar su conducta de abuso y violencia. La psicoterapia, ya sea individual, familiar o grupal, no es el modelo preferido de intervención.

- Los facilitadores de estos programas psicoeducativos corresponden a una variada gama de profesiones: muchos son activistas del sistema judicial que mantienen un interés en temas de masculinidad, temas de hombres, genero y equidad-justicia. Otros son consejeros de servicios sociales o de programas de abuso de sustancias y un grupo considerable pertenece a consejeros con postgrados en salud mental. En muchas instancias, los defensores de las mujeres maltratadas co-facilitan los grupos. Muy pocos facilitadores de grupos son trabajadores sociales clínicos o psicólogos..

- La mayoría de los programas mantienen contacto con las víctimas o con los servicios para mujeres maltratadas que trabajan con las parejas de los HOVIF.

- La inmensa mayoría de programas requieren que los participantes autoricen a los facilitadores a recibir y compartir información con otras instancias del sistema judicial.

Es importante destacar que el terreno para el surgimiento de estos programas fue allanado históricamente por el movimiento de mujeres maltratadas en la década de 1970. Este movimiento surgió como un ramal del movimiento de liberación de las mujeres de finales de 1960 y comienzos de los 1970, que a su vez surgió de movimientos masivos sociales tales como el movimiento de derechos civiles y las protestas en contra de las guerras (de Corea y sobre todo de Vietnam). También obedecen al ingreso de miles de mujeres a la fuerza laboral en Estados Unidos de America y en Europa en la década de 1960.

\section{La Violencia Doméstica se ha ido volviendo un tema de Agenda Nacional en muchos Países}

Basados en el análisis feminista, el movimiento de mujeres maltratadas tomó ciertos pasos que hicieron de la violencia doméstica parte de la agenda social nacional en los países de América del norte primero, en los países de Europa del Oeste después, y en Centro y Sur América después.

1. Dentro de las relaciones maritales, se redefinió el uso de la fuerza como abuso y maltrato. Antes de 1970, el abuso a las esposas era trivializado cada vez que surgía el tema en la literatura clínica

2. Se retiró el velo de lo privado (dicotomía mundo público/mundo privado) que envolvía a las relaciones maritales.

3. Se ubicó el problema de la violencia de los hombres hacia las mujeres en el contexto social.

4. Se desató una campaña pública de gran escala para concienciación pública, asociaciones comunitarias, construcción de instituciones y cambios institucionales y legislativos. 
Invest. pens. crit.

Vol. 2, No. 3, enero- abril 2014.

pp. $59-77$

\section{El Problema de las Primeras Intervenciones de Consejeros Matrimoniales}

La visibilización del problema del maltrato a través del trabajo de las organizaciones comunitarias y el profundo reencuadre social en torno al problema del maltrato, crearon el escenario para los primeros programas de intervención para ofensores. A medida que se fueron estableciendo los programas de atención a hombres ofensores, las respuestas por parte de los sistemas organizados de salud (ministerios, oficinas de salud, etc.) fue lenta o pobre, muchos/as trabajadores/as de salud mental no estaban interesados en al violencia doméstica y no le prestaban atención. El único sector que estaba dispuesto a trabajar con violencia era el de la consejería matrimonial y terapia familiar, donde asistían muchas mujeres maltratadas con sus esposos.

Según relata la investigación documental de Aldarondo, estos encuentros fueron en muchas ocasiones desastrosos. Los consejeros matrimoniales eran entrenados en esa época para mejorar la comunicación y la negociación. Estos terapeutas estaban motivados a ver la dinámica de la pareja desde una causalidad circular y creían en la neutralidad en la terapia, por la importancia de no asignar culpa y no rotular a los pacientes. Irónicamente los enfoques tradicionales de familia y pareja enfatizaban la función, diferenciándose de los enfoques psicoanalíticos que le prestaban atención a tratamientos de largo plazo que pretendían desenterrar patologías.

Sin embargo, esta aparente forma de ver las cosas en terapia dejaba, conceptual y estratégicamente a los terapeutas imposibilitados de hacerle frente a la violencia. Los terapeutas de familia y pareja no estaban preparados para dar una respuesta definitiva, ni un frente común de que la violencia no está justificada, de que la violencia en la familia es una violación de las relaciones familiares y persiste en crear una diferencia de poder en las relaciones entre hombres y mujeres. Además, la forma en que trabajaban estos terapeutas, en grupos donde se promovía que los miembros de la familia hablaran abiertamente y dijeran lo que sentían, fortalecía a las mujeres a hablar sobre la situación de violencia que vivían con sus esposo y revelaran sentimientos de querer abandonar a sus parejas, sin considerarlos riesgos que esto le pudiera traer a ellas.

Muchas de estas intervenciones eran bien intencionadas, por ejemplo, muchos terapeutas motivaban a sus pacientes a hablar desde ellos usando frases que inicien con "yo" y no favorecían los secretos. Estas intervenciones creaban una escalada de la violencia y la agresión de los hombres. Muchas veces estas intervenciones favorecían que las mujeres hablaran sobre sus sentimientos en torno a la violencia y, cuando lo hacían, esto resultaba en ataques vengativos por parte de los maridos, justo después de la sesión, a veces en el estacionamiento o dentro del auto camino a casa.

Enseñarles a las pacientes prácticas de decir la verdad cuando el resultado probable sería que les pegaran era y es mala terapia. La visión circular de la causalidad de estos terapeutas, evitaba que la violencia de los hombres pudiera verse como el tema principal del tratamiento y esta forma de trabajar dejaba a las mujeres más y más aisladas dentro del maltrato y más impotentes al momento de buscar ayuda. 
Invest. pens. crit.

Vol. 2, No. 3, enero- abril 2014.

pp. $59-77$

Esta situación creo un alto nivel de aprensión hacia la práctica de la salud mental por muchas personas dentro del movimiento de mujeres maltratadas y estas intervenciones fallidas fueron determinantes en que se desarrollaran los PIOs.

A partir de este momento, se establecieron programas diseñados para trabajar sistemáticamente -no sistémicamente- en que los hombres lograran reconocer su maltrato. Esta nueva ola de facilitadores entendían muy bien que era imposible hacer alianzas con los HOVIF y que esto dejaría a las víctimas en una posición de mayor vulnerabilidad.

\subsection{La Primera Generación de Programas de Intervención a Ofensores (PIO)}

Etiony Aldarondo considera, y esta es una aseveración históricamente comprobada, que los programas "Emerge" y "Raven" fueron los programas pioneros que surgieron como un pedido por parte del movimiento de mujeres maltratadas para atender a los HOVIF. Estos programas fueron creados con la intención de atender y revisar los errores que habían ocurrido en el pasado y pudieran atender el problema de la violencia del hombre, buscando trabajar nuevas formas de socialización más equitativas y que llevaran a los hombres a formas de interacción menos basadas en la violencia. Estos programas reconocían que la violencia en la pareja era utilizada como una estrategia para mantener el poder de la relación y tenían como característica, alejarse de los modelos médicos o psicoterapéuticos.

El rango de intervenciones de estos programas rápidamente se movió de detener la violencia de los hombres. Estos primeros intervencionistas o facilitadores en sus primeros encuentros con los hombres, prestaron mucha atención a las mujeres maltratadas y a los defensores de estas mujeres y descubrieron que el problema con la violencia de los hombres no radicaba exclusivamente en la expresión de la violencia física, sino que muchos hombres tenían formas particulares de mantener el control que constituían un estado permanente de coerción e intimidación.

La investigación científica que se llevó a cabo durante esta etapa determinó claramente que los HOVIF utilizaban -y utilizan- una amplia variedad de conductas para mantener la intimidación de sus parejas: desde miradas, cambios en el tono de voz, uso constante de la rabia y agresividad, gritar, tirar objetos. Las parejas de los HOVIF manifiestan que además de estas conductas penetrantes de violencia e intimidación físicas, ellas también eran víctimas de maniobras constantes de intimidación psicológica. Eran objeto de críticas, acusaciones celosas, ridiculizadas, monitoreadas, desacuerdos en base a acuerdos, desautorizarlas frente a sus hijos, reprimiendo afecto, ignorándolas. Existía en estos hombres una sensación de tener un derecho autoasignado sobre sus esposas; esto se manifiesta en la relación de muchas maneras: los hombres se sienten que mandan en la relación, controlan la vida social de sus esposas, controlan las finanzas de la pareja, exigen disposición sexual de sus mujeres y oros abusos similares. 
Invest. pens. crit.

Vol. 2, No. 3, enero- abril 2014.

pp. $59-77$

\section{Redefiniendo Maltrato en los programas de la primera generación}

Estos primeros facilitadores de los programas "Emerge" y "Raven" redefinieron maltrato como un patrón continuo de control coercitivo que incluye intimidación, abuso psicológico y un desproporcionado sentimiento de posesión de sus parejas que el maltratador o golpeador mantiene y refuerza a través del uso de la violencia. La intimidación provoca en las mujeres miedo y las hace retroceder y aislarse, haciéndolas menos asertivas, muchas veces como un mecanismo de auto protección. El abuso psicológico las aísla, destruye la autoestima y hace de las mujeres más dependientes del control externo. La exagerada manifestación de pertenencia de los hombres hacia las mujeres las hace ignorar su propias necesidades y deseos, además las hace estar más pendientes de las necesidades de los hombres. Dentro del modelo de violencia coercitivo, la violencia física es apenas una forma de mantener el control. Sin embargo, la violencia física es la forma más alarmante de control y compulsión y cuyos efectos son más destructivos.

\section{Enfoque sobre Responsabilidad}

Los objetivos de las intervenciones en estos modelos de primera generación se movieron, de detener la violencia física a trabajar sobre las formas que los hombres se sienten en derecho de posesión de las mujeres. Este salto cualitativo se hizo patente en programas o modelos como Manalive, como el Centro de Recursos para Hombres de San Francisco y el modelo de Duluth. En el momento en que se hace a los hombres responsables (un término que entró en uso en los 80s), hacía referencia en hacer a los hombres responsables por detener la violencia intrafamiliar.

\section{Contacto con las Parejas}

Estos programas desarrollaron una modalidad de trabajo en la que se incluían entrevistas confidenciales a sus parejas. Muchos programas incluían un contrato en el que los ofensores o maltratadores aceptaban que alguien del programa visitara a miembros de su familia como un requisito de participación en el programa. El contenido de estas visitas nunca era divulgado con los hombres. Estas visitas tenían como finalidad ayudar a las mujeres a conocer o acceder a programas de atención a mujeres maltratadas o a servicios públicos para ellas, también cumplía con la finalidad de obtener por parte de las mujeres el manejo de la violencia por parte de sus esposos, para tener mejores y mayores elementos para evaluar la peligrosidad de la violencia de estos hombres. Estos encuentros también servían para que las mujeres pudieran estar al tanto de situaciones potenciales de peligro para ellas.

\section{Preocupaciones Especiales en los programas para HOVIF de la primera generación}

Los PIOs de esta primera generación, jugaron un protagonismo especial en estos logros. Sin embargo la vigilancia hacia el recelo hacia el sector salud, generó una serie de preocupaciones. 
Invest. pens. crit.

Vol. 2, No. 3, enero- abril 2014.

pp. $59-77$

- Que los miembros del equipo realizaran intervenciones que colocaran en riesgo o en peligro a las víctimas de abuso, como revelar información que sus parejas hayan divulgado sobre el ofensor o que no le informaran a las mujeres sobre indicadores de peligro para ellas o aumento en la agresividad de estos hombres.

- Que los miembros de los programas desarrollaran intervenciones que los llevaran a apoyar ciegamente a los ofensores y desarrollar intervenciones de tipo empáticas; más que en el cambio conductual y la detención de la violencia o conducta abusiva.

- Que algún miembro del equipo del programa conciente o inconcientemente aceptaran la justificación para el abuso de los HOVIF, o que aceptaran que la conducta abusiva es el resultado de un patrón de intervención. Esta tendencia es llamada "colusión” y continua siendo una preocupación actual en los programas a HOVIF.

- Que los PIOs compitieran o trataran de monopolizar las oportunidades para financiamiento dirigidos a apoyar albergues para mujeres maltratadas o programas para la atención de mujeres maltratadas.

\section{Avances significativos de los PIOs de primera generación}

En sentido general esta primera generación de programas de intervención produjo logros importantes y duraderos en distintas áreas:

- Crearon una alternativa a los servicios inapropiados brindados por el sector de Salud Mental.

- Crearon una perspectiva teórica para explicar la violencia de los hombres hacia las mujeres como una práctica (1) históricamente enraizada en la supremacía masculina y la asimetría en la distribución del poder y (2) se mantiene a través del apoyo de la sociedad, mediante la inhabilidad por parte de distintas instituciones sociales (iglesia, sistemas de salud, sector judicial y policial) de hacer a los hombres responsables de su conducta violenta y en proveer servicios para las víctimas.

- Desarrollaron un entendimiento práctico del abuso que reflejaba la experiencia de las mujeres maltratadas y que permitió que se formularan intervenciones educativas apropiadas con HOVIF.

- Inventaron y modificaron la estructura básica de los programas y de las técnicas que todavía continúan en uso hasta hoy.

- Permitieron el espacio para que otros hombres pudieran públicamente condenar la violencia, relaciones de maltrato y la supremacía masculina en nuestra sociedad (patriarcado 
Invest. pens. crit.

Vol. 2, No. 3, enero- abril 2014.

pp. $59-77$

hegemónico) y también permitió la alianza con mujeres en el movimiento en contra del abuso y maltrato hacia las mujeres. Lucharon conjuntamente por crear cambios en las políticas sociales y a partir de esto surgió el entrenamiento para profesionales del sector salud.

- Desarrollaron relaciones largas con los programas a mujeres maltratadas.

\section{Limitaciones de los PIOs de primera generación}

Pero de la misma manera, estos programas de primera generación, a pesar del compromiso por hacer a los hombres responsables y por desarrollar alternativas a los modelos de intervención clínicos, proveyeron servicios de una forma en la que se reproducían algunas limitaciones que sufrían los programas de salud mental. Los PIOs eran en esencia encuentros privados de un número minúsculo de hombres y su consejero.

Si bien durante esta primera generación se produjeron cambios y surgió la oportunidad de condenar públicamente la supremacía masculina como agente principal de las situaciones de violencia; estas intervenciones fueron mínimas. Con la segunda ola esta situaciones cambian y los grupos cobran nuevos y mayores protagonismos que los ayudan a salir del anonimato en el que estaban.

\subsection{La Segunda Generación de programas de atención a ofensores}

Tres factores influyeron para que se ampliara el rol social de los programas a ofensores:

- El desarrollo del modelo de respuestas coordinadas comunitarias a la violencia doméstica.

- La creación de un programa completo de intervenciones diseñadas sesión por sesión, para intervenciones con grupos HOVIF que pudieran ser adaptadas por diversos facilitadores con relativa facilidad en el contexto del modelo de respuestas comunitarias coordinadas a la violencia doméstica.

- Se promovió un interés nacional para la estandarización de los PIOs que formalmente adoptaban y apoyaban las intervenciones que surgieron de los programas de la primera ola de PIOs.

El Proyecto de Intervención para Abuso Doméstico (PIAD) en Duluth, Minnesota, fue instrumental en el desarrollo de respuestas comunitarias coordinadas y en la creación del currículo completo para programas con abusadores. Fundado en 1980, el PIAD se convirtió en una fuente de influencia perdurable para la innovación para formas de intervención institucional en violen- 
Invest. pens. crit.

Vol. 2, No. 3, enero- abril 2014.

pp. $59-77$

cia doméstica. El proyecto comenzó como un intento por organizar los programas institucionalizados en defensa a las mujeres maltratadas para que mejoraran la coordinación entre el gobierno y las agencias públicas que intervienen en las situaciones de violencia.

La defensa institucional del PIAD procuró coordinar las actividades de diversas instituciones del sistema penitenciario judicial por:

1. Crear una visión completa de seguridad para la víctima.

2. El desarrollo de políticas de "mejores prácticas" y protocolos de intervención para agencias que forman parte de un sistema integrado de respuestas.

3. Realzar los establecimientos de redes (networking) entre los proveedores de servicios.

4. La edificación de sistemas de monitoreo y seguimiento.

5. Asegurar un sistema de infraestructura de apoyo comunitario.

6. Proveyendo oportunidades de sanción y rehabilitación para HOVIF.

7. Deshacer el daño que la violencia provoca en mujeres y niños/as.

8. Evaluar la respuesta coordinada comunitaria desde el punto de vista de la seguridad de la víctima (Pence y Shepard, 1999).

\section{El Reencuadre del concepto de "responsabilidad" a un tema de interés judicial}

El logro de este encuadre institucional significó en Duluth que muchos más hombres fueran arrestados ya que la policía implementó una sólida política pro-arresto; esto también se benefició porque existían mejores expedientes policiales sobre la situación de violencia y que los hombres que fueron condenados se les ofreció la oportunidad de cumplir su condena o de ser colocados en custodia con la condición estricta de no incurrir en futuros actos de violencia y asistencia obligada al PIO de Duluth. Los departamentos de custodia de los servicios correccionales monitoreaban a los PIO y la no adhesión a esto, resultaba en encarcelamiento. Esto aumentó dramáticamente el número de referencias y derivaciones de los HOVIF y presionó a estos hombres a participar y completar sus condenas en estos servicios.

Estas nuevas prácticas reencuadraron la "responsabilidad" como una tarea compartida de varias instituciones. Previamente, que un hombre fuese "responsabilizado" en un PIO significaba que los consejeros o facilitadores podían impulsar a los hombres a hacerse responsables de su conducta violenta y cambiarla, que se validara la perspectiva de que no es culpa de la mujer y que se refiriera a estas mujeres a un programa para mujeres maltratadas o al sistema judicial. Dentro del programa de respuesta coordinada comunitaria de Duluth, los facilitadores de los grupos de hombres eran responsables por proveer información al sistema de custodia y sobre los requisitos de la custodia, como la puntualidad, la asistencia; el no cumplimiento de estas medidas podría resultar en el encarcelamiento del HOVIF. La respuesta coordinada entre los PIOs, el sistema judicial y correccional le dio a los PIOs el poder de poder ejercer presión sobre los HOVIF. 
Invest. pens. crit.

Vol. 2, No. 3, enero- abril 2014.

pp. $59-77$

\section{La sistematización curricular y manualización a través de un Plan de estudios Educativo}

El plan de estudios paso a paso del PIAD para intervención con HOVIF (llamado el modelo Duluth) fue lanzado en 1990 (Pence y Paymar, 1990). Este plan de estudio sirvió después de insumo a muchos programas de atención a HOVIF en muchas latitudes y países del mundo, de Europa, Centro y Sur América. Los programas en uso en ese momento (por ejemplo, Raven y Emerge) confiaban excesivamente en el "proceso de grupo" para ayudar a los hombres a cambiar su conducta violenta. En estos modelos la mayoría del tiempo en grupo era invertido en discusiones abiertas, pero controladas sobre negación, minimización, culpar a la víctima y el control de conductas abusivas y controladoras. Se esperaba de los hombres que admitieran sus actos de violencia y abuso, que exploraran sus necesidades de control en profundidad, que consideraran conductas alternativas y que se dedicaran ellos mismos a conductas remediales o planes de seguridad o protección.

Los facilitadores también dirigían discusiones para concienciarlos sobre su conducta, mejorar la expresión de sentimientos (auto conocimiento emocional mas allá de la rabia estereotipada del varón), juego de roles, y las variadas formas de abuso de los hombres y el control hacia la mujer. Algunos programas reforzaban la confrontación para presionarlos a que divulgaran su conducta violenta y a acordar cambiar esta conducta; otros programas enfatizaban un enfoque más de apoyo que reconocía que los roles fijos de los hombres promovía la conducta abusiva. Estos programas enfatizaban el aumento en la expresividad emocional y la formación de comunidades de apoyo de hombres a favor de la igualdad y de conductas no abusivas hacia las mujeres. Sin embargo, ambos modelos exigían consejeros que adoptaban una perspectiva abiertamente feminista sobre la violencia masculina y que habían participado en un proceso prolongado de preparación y sensibilización para facilitar estos programas. Por lo tanto, contratar personal para implementar estos modelos era un proceso lento que favorecía a consejeros que estuvieran dispuestos a comprometerse a largo plazo con los programas.

\section{El plan de estudios del Modelo Duluth: un ejemplo típico de programas de Segunda Generación}

El modelo de Duluth facilitó esta acumulación de los programas anteriores, desarrollando un "paquete" de plan de estudios o currículo (Pence y Peymar, 1990; 1993) con planes detallados de lecciones para un programa de 27 semanas de dos horas cada sesión, de las cuales tres sesiones son lecciones de orientación. Las 24 restantes sesiones se dividen en 8 unidades de 3 módulos cada una. Ya que este modelo es el que se utiliza con mayor frecuencia en el campo, es de provecho describirlo con mayor cabalidad.

Estructuralmente, cada lección de 3 clases, en esencia, repite el mismo ciclo. En la primera lección de cada ciclo, los hombres definen y exploran ejemplos de una conducta abusiva e instancias de su uso propio de la conducta "blanco" abusiva, y en las otras tres ellos aprenden y practican las habilidades interpersonales que necesitarán para aplicar la alternativa equitativa a los patrones de relacionamiento abusivos. Por ejemplo, la segunda unidad de tres ciclos se enfoca en abuso 
Invest. pens. crit.

Vol. 2, No. 3, enero- abril 2014.

pp. $59-77$

emocional versus respeto. En la primera lección los participantes definen respeto y analizan un video ilustrando escenas en que un hombre es emocionalmente abusivo hacia su pareja. En la segunda lección ellos analizan ejemplos de sus propios estados de abuso emotivo hacia sus parejas, y en la tercera lección practican interacciones respetuosas en juego de roles que evocan episodios conflictuados de sus propias relaciones (Pence y Peymar, 1990).

Conceptualmente, el modelo de Duluth personifica una aproximación feminista-cognitivo-conductual. Es feminista en la medida en que el abuso es identificado como una forma de opresión hacia la mujer y el programa se adscribe a la visión de equidad entre hombres y mujeres como el ideal hacia el que todos los HOVIF deberían moverse en sus relaciones. Es una aproximación cognitivo-conductual en el sentido de que (1) se enfoca en ayudar a los HOVIF a que cambien creencias que justifican la supremacía masculina y el control coercitivo hacia las mujeres y (2) enfatiza aprender y practicar nuevas habilidades interpersonales que apoyen al cambio.

\section{La incorporación del Diálogo Crítico, auto-reflexivo: el trabajo de Paulo Freire}

El trabajo cognitivo está basado en el trabajo de Paulo Freire (1970), un educador brasileño pionero en el campo de los programas de alfabetización para adultos desposeídos en su país. Cuando en un principio intentó enseñar a leer, Freire descubrió que muchos campesinos brasileños carecían de motivación para aprender a leer. Eran incapaces de tener una visión de sí mismos fuera de la pobreza, bajo el control y opresión de grandes terratenientes. En vez de verse a sí mismos como victimizadas por fuerzas sociales poderosas, ellos creían que sus precarias existencias eran el resultado del orden natural de las cosas y que aspirar a cualquier otra cosa estaba más allá de sus capacidades. ¿Para qué complicarse queriendo aprender a leer? Freire no se sorprendió ante esta forma de pensar. Él pensaba que nuestra sociedad occidental estaba permeada por un autoritarismo jerárquico o por relaciones basadas en la autoridad. En un sistema de relación jerárquico, un grupo de personas establecen el control hacia los demás y lo mantienen a través del control coercitivo y por medio de popularizar sistemas de creencias que fomentan y permiten relaciones desiguales de poder.

Estos sistemas de creencias están profundamente arraigados en la mente de las personas que viven bajo estos sistemas de dominación jerárquico. Tanto los opresores como los oprimidos creen y han internalizado esas doctrinas. Con el tiempo ambos grupos quedan atrapados en estos patrones de relación; por supuesto que el rol de los oprimidos es el de mayor desventaja; sin embargo también piensan que estas formas de relaciones basadas en el control jerárquico son inevitables.

Freire pensaba que si este grupo de campesinos cambiaban sus creencias sobre sí mismos y sobre la forma en que son las cosas, a través del desarrollo de habilidades analíticas con la ayuda de un profesor altamente empático, podrían motivarse a leer y cambiar sus circunstancias a través de acciones políticas en su beneficio. De tal manera, Freire desarrolló un grupo llamado “diálogos 
Invest. pens. crit.

Vol. 2, No. 3, enero- abril 2014.

pp. $59-77$

críticos y auto-reflexivo" para ayudar a que personas en esta situación pudieran analizar y entender, cómo su propio raciocinio de ellos mismos y otros, justificaba circunstancias jerárquicas y opresivas; y los ayudaba a considerar y poner en práctica alternativas no-opresivas.

Freire inició su programa educativo mostrando una serie de fotos o imágenes de situaciones típicas de la vida de estos hombres y mujeres y sobre estas fotos se hacían comentarios; de estos comentarios Freire iba hilando los pensamientos jerárquicos internalizados que poseían estas personas. Estas historias constituyeron la base de los diálogos críticos y de auto reflexión en los cuales las personas y sus ideas jerárquicas eran continuamente cuestionadas hasta que simplemente, por medio de la confrontación gradual a estas ideas, las personas iban cambiando su forma de verse a sí mismos.

Los diálogos críticos y auto reflexivos pueden incluir preguntas como las siguientes:

- ¿De dónde surgen sus ideas sobre maestros, acerca de las personas educadas y sobre el silencio?

- ¿Quién se beneficia de esto?

- ¿Quién tiene desventaja desde su punto de vista?

\section{La Adaptación del modelo de Freire al trabajo con HOVIF}

Pence y Peymar adaptaron el modelo de Freire para el trabajo con ofensores. Primeramente teorizaron que la conducta violenta es una forma de opresión que los hombres tienen bajo su poder o que utilizan como parte de ser hombres o de su masculinidad. Estas creencias pueden ser (1) dogmas, creencias incuestionables que vienen de la Biblia o de otra fuente similar de autoridad; (2) es una parte inmutable de la naturaleza que surge de nuestra herencia genética; o (3) es un elemento de la masculinidad, es algo que creen es parte inherente de la identidad masculina y que no puede ser desechado sin deshacer o destruir la masculinidad.

Pence y Peymar también adaptaron los diálogos críticos y auto reflexivos del método de Freire. En vez de enseñarles fotos a los grupos, desarrollaron una serie de cintas de vídeo mostrando escenas breves o viñetas que ilustran diferentes formas de abuso en encuentros entre hombres y mujeres. Estas viñetas fueron desarrolladas como resultado de investigaciones con grupos focales con mujeres maltratadas en Duluth que hablaron sobre sus experiencias de maltrato. Luego ver estos vídeos, el grupo participaba en un ejercicio de bitácora de control (Pence y Peymar, 1986). La bitácora de control tiene una serie de preguntas estructuradas sobre las siguientes áreas:

¿Qué hizo el hombre? ¿Puede mencionar conductas abusivas?

¿Cuál era la meta del hombre? 
Invest. pens. crit.

Vol. 2, No. 3, enero- abril 2014.

pp. $59-77$

¿Qué creencias tiene el hombre que justifica su conducta?

¿Cuál fue el impacto de la conducta del hombre sobre su mujer?, ¿`sobre sí mismo?, ¿'sobre los miembros de la familia?

¿Cómo minimizó o negó su violencia? ¿Cómo pudo comportarse de un modo diferente? ¿Qué creencias o pensamientos lo ayudarían a cambiar este comportamiento?

Mediante el análisis y la discusión de conductas de hombres como ellos, los participantes del grupo comenzaban a experimentar lo que ellos y otros hombres hacen como resultado de su elección y como resultado de sus creencias que pueden ser cambiadas.

\section{La incorporación del Ambiente de no confrontación}

El manejo de tratar la violencia del grupo a través de los diálogos auto reflexivos tenía la peculiaridad de crear un ambiente de no confrontación en la que los miembros no se sentían instigados a tener ser confrontados ante su conducta violenta, era más gentil hacerlo de este modo y también era más fácil ver a estos hombres como víctimas de un sistema de creencias y valores más que como monstruos.

\subsection{La Tercera Generación de Programas de Intervención a HOVIF}

La tercera ola de PIO ha intentado ampliar el espectro de programas de intervención mientras se sigue mintiendo el enfoque en la responsabilización del hombre de sus conductas abusivas y el aprendizaje de formas de relacionamiento no abusivas. Como parte de esta tercera ola o generación de programas se pueden incluir el programa de Reintegración Social de Almeida (AMEND) y Manalive a pesar de que son grupos que fueron establecidos durante los ochentas y noventas.

Bajo el riesgo de inventar un movimiento que no existe, no existe ningún grupo que se auto reconozca como de tercera generación, sin embargo podemos decir que existen un grupo de programas que aplican al menos uno, con frecuencia más de las siguientes características:

1. Que enfoquen la creación de comunidades de afirmación no sexista.

2. Enfoque holístico que aborde estos temas como:

a. Las historias de victimización de hombres físicamente abusivos y su conexión con su conducta agresiva como adultos.

b. La conexión entre raza/etnia, nivel social, temas de clase, del contexto de la vida, masculinidad y violencia doméstica.

c. La conexión entre salud mental y el desarrollo de problemas (incluyendo las distorsiones cognitivas y temas sobre el apego) y la violencia doméstica.

d. La conexión entre las experiencias de hombres con padres físicamente abusivos y su propia adultez abusiva. 
Invest. pens. crit.

Vol. 2, No. 3, enero- abril 2014.

pp. $59-77$

\section{Apoyando la capacidad de los hombres por elegir la no violencia}

Todos los programas arriba mencionados enfatizan la responsabilidad como punto principal de los programas coordinados de respuesta comunitaria. Todos ellos ayudan a los hombres distinguir conductas abusivas y de control y enseñarles alternativas a la violencia. Estos programas representan la habilidad que tienen los hombres por elegir y practicar conductas no violentas. Muchos de estos programas tienen una perspectiva holística. A pesar de que muchos programas se diferencian sustancialmente los unos de los otros, la elaboración de programas de perspectiva holística subraya el supuesto de que existen muchos factores que pueden tener efectos protectores para prevenir la situación de violencia y que pueden promover respeto hacia la mujer y que reconozcan su capacidad de autodecisión. Por ejemplo, los programas basados en las diferencias culturales ayudan a los hombres a recuperar partes de bagaje cultural que promueve respeto hacia las mujeres y favorece relaciones de mayor igualdad.

Los programas que visualizan la historia de victimización de los hombres los ayudan a reconocer y sanar sus historias traumáticas y los animan a comprender a cómo han utilizado su victimización pasada para generar abuso en el presente. Los modelos que enfatizan temas de salud mental son particularmente eficientes ayudando a los hombres a autoadministrarse y a desarrollar habilidades sociales apropiadas para optar en vez de las conductas de abuso. Incorporar temas de paternidad al programa para HOVIF se basa en el convencimiento que muchos hombres son impactados de una manera muy positiva cuando comienzan a entender el efecto que tiene en sus hijos/as el hecho de ser testigos de la violencia contra sus madres. Para muchos hombres esta es una motivación poderosa.

El reto de los programas que forman parte de la tercera ola o generación guardan como reto el poder incorporar los temas de violencia masculina a la gente de la calle, o sea, hacerlos accesibles más personas y en ese sentido a futuro se plantean el poder lograr una prevención primaria adecuada, incluyendo los temas de masculinidad, violencia masculina y equidad en las relaciones entre hombres y mujeres a nivel de las escuelas, como parte de las charlas matrimoniales, charlas en las iglesias, programas de estudios universitarios; en fin, que el tema de la violencia pueda llegar a un mayor número de personas y que se maneje en distintos niveles de la sociedad.

Esta revisión histórica se convierte en un marco desde donde el cual entender el desarrollo de las atenciones a HOVIF en Panamá y sirve como preámbulo a la descripción de los programas de atención a HOVIF en Panamá.

\subsection{La Situación Histórica de la Atención a los Problemas de la Violencia Doméstica en Panamá}

Luego de la invasión de Estados Unidos a Panamá, en 1989, y con el advenimiento de la democracia, el movimiento de mujeres logra organizarse más aún y consolidarse con la creación del Foro Mujer y Desarrollo para el año 1992. En este foro logran presentar el primer Plan Nacional 
Invest. pens. crit.

Vol. 2, No. 3, enero- abril 2014.

pp. $59-77$

Mujer y Desarrollo 1994-2000. El Plan se torna una guía para todas las políticas, planes, proyectos y programas que se pusieran en marcha posteriormente. La atención a hombres ofensores aparece en nuestro país como un resultado un tanto fortuito en el continuo de una serie de decisiones diseñadas para conceder a la mujer mayor protagonismo, y hacer de esta manera que salieran de su invisibilidad jurídica.

De manera coyuntural coinciden una serie de factores que facilitan las primeras decisiones en pro de las mujeres con la proclamación de la "Ley N 4 de enero de 1999 de Igualdad de Oportunidades", que de alguna manera fue la ley pionera que ha impulsado otras medidas o leyes que han beneficiado directamente a las mujeres panameñas en los últimos 10 años. Estos hechos tienen que ver con el compromiso del Presidente de la República Ernesto Pérez Balladares (19941999), que creó el Ministerio de la Juventud, la Mujer, la Niñez y la Familia (MINJUNFA). Además de la elección de la Legisladora Gloria Young, feminista de trayectoria en Panamá, y la presencia en Panamá de la oficina de ProIgualdad de la Comunidad Europea, entidad dirigida a fomentar actividades en torno al género y la mujer.

Es a través de las gestiones de ProIgualdad que comienzan a proliferar una serie de ONGs dirigidas al trabajo con las mujeres y comienzan las labores de mapeo e identificación de puntos críticos en la vida de las mujeres. Gloria Young, como legisladora de la República, se compromete con el Movimiento de Mujeres a través del Foro Mujer y Desarrollo a presentar frente a la Asamblea de Legisladores proyectos de Ley que favorezcan a las mujeres. Es en ese interés que se inicia el Centro de Apoyo a la Mujer Maltratada (CAMM).

\subsection{La Historia de la Atención a HOVIF en Panamá}

La Organización Panamericana de la Salud aprobó la Resolución XI de 1993 donde reconoce la importancia del problema de la violencia y se establece la necesidad de formular nuevas políticas y directrices para el sector Salud. Es entonces cuando se impulsa el Plan Regional de Sección sobre Violencia y Salud, promoviendo la realización de estudios que logren conocer de fondo las dinámicas y formas particulares que toma la violencia (hacia la mujer), sus manifestaciones políticas, sociales, en cuanto al género, escolar, infantil, en las familias; y las implicaciones que esto tiene con la salud.

La historia de la Atención a HOVIF en Panamá está vinculada a la aparición del CAMM. Este se crea en 1994 con el objetivo de ayudar a mujeres sobrevivientes de violencia intrafamiliar a través de los servicios de asesoría legal, servicios de trabajo social y salud mental. Junto a otras ONGs, el CAMM desarrolla un trabajo de visibilización de la problemática de la violencia doméstica en la década de 1990.

Contando con un equipo interdisciplinario diseñado para trabajar con la atención de las mujeres víctimas de violencia intrafamiliar, el CAMM empieza a acumular experiencias y a definir su visión de problema. Es con el trabajo con las sobrevivientes de violencia física (las mujeres) que 
Invest. pens. crit.

Vol. 2, No. 3, enero- abril 2014.

pp. $59-77$

el CAMM comienza a sentir la imperiosa necesidad de trabajar también con los ofensores, los hombres violentos. Aun cuando el feminismo radical, y muchas de las feministas tradicionales en Panamá, no creían en la postura de recuperación de los hombres violentos, otro grupo de feministas en Panamá favorecieron la aparición de iniciativas de atención sistémica e integral de la violencia intrafamiliar, inclusive la posibilidad de atención a los hombres ofensores.

Entre 1994 y 1999 el CAMM trabaja atendiendo, capacitando y desarrollando una iniciativa de atención a las mujeres víctimas de VIF. En los mismos años el CAMM dirigió el primer estudio de Violencia Doméstica, financiado por el BID, donde se dio capacitación a funcionarios del órgano judicial, y los equipos de Salud. Hasta 1999, el CAMM trabaja únicamente con mujeres. En ese año se desarrolla en Panamá un taller de masculinidad con algunos expertos en el tratamiento de la violencia doméstica. Un grupo de los hombres asistentes deciden formar un círculo de reflexión permanente sobre temas de masculinidad. Entre 1999 y 2002 este grupo de hombres pasan por un proceso de reflexión personal y revisión del impacto de la masculinidad en sus vidas, donde vivencian y admiten cómo habían sido violentos de diferentes modos y cómo la violencia había impactado sus vidas.

En marzo 16 de 2002 abre oficialmente la Clínica de la Masculinidad, y el Grupo de Apoyo a Hombres Ofensores (GAHO). Expertos de diferentes países, como México, Costa Rica y Estados Unidos (psicólogos, trabajadores sociales, psiquiatras, etc.), y de diferentes programas (como CECEVIM en Estados Unidos, y Coriac en México) capacitaron a panameños sobre temas de atención a hombres ofensores.

Las principales actividades del Actividades que llevaba a cabo el GAHO eran:

1. grupos de apoyo a hombres ofensores;

2. la formación institucional;

3. la coordinación para la atención de los HOVIF con el Ministerio de Salud (MINSA), la Caja del Seguro Social (CSS), el Órgano Judicial, las Fiscalías, y las Corregidurías;

4. la divulgación y la educación en temas de masculinidad.

Los objetivos del GAHO eran:

1. Eliminar la conducta violenta en todas sus formas.

2. Estimular la toma de conciencia y la responsabilidad personal de los hombres por su conducta violenta.

3. Propiciar una revisión personal acerca del impacto negativo de la violencia ejercida y recibida a lo largo de la vida.

4. Facilitar la alfabetización emocional.

5. Estimular nuevos modos de vivir la masculinidad.

El formato de trabajo terapéutico del GAHO era: 
Invest. pens. crit.

Vol. 2, No. 3, enero- abril 2014.

pp. $59-77$

1. Grupo psicoeducativo, abierto, para HOVIF referidos legalmente, y hombres con problemas de poder y control.

a. Coordinado por un facilitador con formación técnica en salud mental, género, violencia, y manejo de grupos.

b. Con apoyo de co-facilitadores voluntarios (de entre los mismos hombres) y cofacilitadores profesionales voluntarios.

2. Grupo de hombres para hombres.

a. Nocturno, 2 horas una vez por semana, durante 24 semanas.

b. En su mayor momento de crecimiento llegó a llevar 3 grupos de hombres ofensores por semana).

c. Los participantes que podían hacerlo, hacían aportes mínimos para recibir los servicios de atención (pagaban entre B/. 0.50 hasta B/. 10.00 por sesión).

El esquema general de las sesiones era el siguiente:

1. Bienvenida y Presentación De Nuevos Miembros

2. Revisión de la Situación Individual y Familiar

3. Relato de Eventos de la semana/ "diario" del enojo

4. Desarrollo del Proceso Restructurativo Cognitivo - Emocional

5. Presentación de un tema Educativo

6. Compromisos De Salida y Abrazoterapia

El modelo de tratamiento del GAHO estaba basado en el modelo CECEVIM (Centro de Capacitación para Erradicar la Violencia Intrafamiliar Masculina). El objetivo de la Red CECEVIM es crear colaboración entre programas para erradicar la violencia masculina y para desarrollar estrategias cada vez más efectivas y amplias para hacer este trabajo. Colaborar y cooperar es uno de los principales retos para la identidad masculina pues cuestiona la estructura jerárquica de las relaciones. Por esto participar en la Red CECEVIM es un ejercicio de colaboración, cooperación e intimidad que permite a todos y todas las participantes crecer para crear comunidades intimas y no violentas y presenta tres focos de atención:

A.- Foco sobre el Individuo: Las intervenciones iban encaminadas a ayudar a cada uno de los hombres asistentes a descubrir su propia responsabilidad y sus propias alternativas frente al uso de la violencia. Ayudarlo a sanar emocionalmente. Se visualizada al individuo como artesano de su cambio, y se creía que nadie tiene el poder de modificar a otro, sino el mismo.

B.- Foco sobre los aspectos de poder y control: Se trabaja desde la perspectiva género-sensitiva para generar conciencia de cómo la ideología, la estructura social y la conducta, se encuentran vinculadas entre sí. Se enfatizaba la responsabilidad personal de cada ser humano o humana en 
Invest. pens. crit.

Vol. 2, No. 3, enero- abril 2014.

pp. $59-77$

la terapia por el cambio. Se reflexionaba insistentemente sobre los micromachismos y la subestimación de la mujer, menosprecio de la pareja, denigración en todas sus manifestaciones, tendencia a invadir el espacio de la mujer.

C.- Foco sobre lo socio cultural y relacional: Se buscaba establecer el control y nuevos vínculos entre pares, contrarrestar mecanismos de autoengaño (minimización, negación, manipulación) a través del intercambio de sus vivencias. De igual forma se buscaba la adquisición en el grupo de nuevos modelos de normas no hegemónicas; la Identificación de emociones, deseos y necesidades. Finalmente, este foco de atención también contenía intervenciones dirigidas a quebrar el aislamiento que muchos HOVIF tienen, a facilitar el aprendizaje de la afirmación personal y nuevos modos de interacción, y el desarrollo personal a través de la ayuda y confrontación mutua.

Aun cuando la contribución del Grupo de Apoyo a Hombres Ofensores fue crucial para el desarrollo de modelos de atención a HOVIF en Panamá, el programa quedó cerrado al dejar de funcionar el Centro de Apoyo a la Mujer Maltratada, del cual dependía económicamente GAHO funcionó hasta la desintegración del CAMM en el 2005. 